\title{
The Pediatrician and Research
}

\author{
FLOYD W. DENNY
}

Department of Pediatrics, School of Medicine, University of North Carolina, Chapel Hill, North Carolina, USA

I should like first to express to the members of the American Pediatric Society my great pleasure on being chosen as your President. This is indeed one of the greatest honors that can come to a pediatrician and I am grateful to all of you for allowing me to serve in this capacity.

I have chosen as the title of my address: "The Pediatrician and Research." There are several reasons behind this choice, one being that pediatricians and research, separately or together, are among my greatest interests. The main reason though is that, as an older member of the academic establishment and a departmental chairman for many years, I have developed major concerns about what is happening to pediatricians and research and where they are going in the future. In this address I want to share with you some of these concerns. Then, by describing some of the research I have been involved with over the past few years, I shall make suggestions for some solutions.

I want to present for consideration the following five areas: (1) Insufficient knowledge to use biomedical information; (2) Lack of outlets for clinical research and teaching; (3) Fewer pediatricians choosing academic careers; (4) Declining interest in clinical research; (5) Dissatisfaction of pediatricians with practice.

At first glance, these may appear to be a disparate group. I believe that there is a common thread between them; I hope I can make this clear as my talk progresses.

The first concern listed is that we have insufficient knowledge to use biomedical information. By this I mean that we have more medical information, facts, and technologies than we know how to use appropriately in our care of patients; and this discrepancy stands to increase drastically in the near future. Let me give you several common examples. We know how to remove tonsils and adenoids but we do not really know on whom this most common of all operations in this country should be performed. We believe that well child care is important; as a matter of fact most pediatricians spend about one half of their time doing this. But we do not know what well child care should consist of or how frequently it should be given. Another prime example is the marvelous, new CT scanner. It is clearly one of the remarkable advances in medical technology, but we do not yet know in sufficient detail how to use it best to benefit our patients.

These are only examples of dilemmas we presently encounter. I remind you that we are on the threshold of the most explosive development of medical knowledge that we have ever known. Genetic recombination, the development of monoclonal antibodies and microelectronics, to mention only a few, will make possible in the near future medical feats that only a few months ago could only be dreamed about. This is all very exciting but I suspect that the discrepancy between this medical knowledge and our abilities to use it well will get larger and larger very quickly. The most disturbing thing to me though is that I cannot detect that we are developing any kind of plan or approach to solve this problem. In any event, this is an area for concern and we must try to find some solutions.

My next concern is the lack of outlets for clinical research and teaching. Let me address teaching first. Most medical school clinical teaching has always been done on hospitalized children. There are several changes taking place in this country which are altering this situation. Advances in the clinical care of sick children have been such that many major diseases have decreased or have disappeared altogether and others can be cared for without hospitalization. Hospital beds for children are decreasing steadily all over the country. In some ways those of us in the teaching game who use tertiary hospitals for teaching purposes are working ourselves out of business. We are developing such capable practicing pediatricians in communities away from our major hospitals that it is no longer necessary or desirable for many sick children to come to our hospitals. Finally, these changing times have seen the need for the pediatrician to address a different set of issues than was present a few years ago. The Task Force on Pediatric Education in its recent publication "The Future of Pediatric Education" has outlined some underemphasized areas in pediatric teaching: biosocial and developmental aspects of pediatrics, handicapping conditions and chronic illness, health maintenance, medical ethics and the organ specific disorders of the musculo-skeletal system, the skin and the teeth, and nutrition. Most of these not only can be taught away from tertiary hospital beds but must be taught in a different setting (8). All of these things dictate the need for new outlets for clinical teaching.

The need for new outlets for clinical research is just as great. I have outlined in my first concern the remarkable explosion of new knowledge. It seems obvious to me that we are going to have to do a great deal of clinical research if we are going to keep pace with this explosion. It is just as obvious that only a small part of this research can be hospital based. The present social climate in this country is not conducive to this kind of research. The present concept of physicians as a bunch of money grubbers, the accent on malpractice and the emphasis on human rights have steadily made the performance of clinical research difficult and at times impossible. Nevertheless, the need for new sites and populations for clinical research is great and we must seek adequate outlets quickly.

My next concern is that fewer pediatricians are choosing academic careers. As I move above this country I am struck by the regularity with which this subject arises. In face of my perception of an increasing need for academicians in pediatrics, this decrease is especially distressing. The reason or reasons for this decrease are not entirely clear but a variety of things come to mind. The salary levels of the academician are not comparable to those of the practitioner. Obtaining support for research is becoming increasingly difficult; I suspect our young people watch us struggle day after day to get research monies and decide it just is not worth it. The long training period now necessary for academia is almost certainly a deterrant. A few years ago a pediatrician could be trained adequately for most academic jobs by 2 years of clinical training and 2 years of fellowship. Now most of us believe that 6 years of training are minimal. Societal pressures to practice medicine have been large for the past few years; similarly the lack of societal pressures to enter academic medicine have been as great. Finally, the general uncertain future of medical academics is doubtless a factor. While the declining interest of young people in academic careers is a concern of all of medicine, we as pediatricians must seek a solution to our problem.

The declining interest in clinical research is the next on my list. This, of course, is part of the previous concern regarding pediatricians entering academics, but not entirely so. We are all aware 
that the knowledge and technologies required to do modern research have increased remarkably in the past few years. This has required that M.D.s compete with Ph.D.s for research dollars; unfortunately this competition is on the Ph.D.'s turf, laboratory oriented research. We are not doing well in this competition. In a recent article in the New England Journal of Medicine by Dr. Donald Frederickson, Director of the National Institutes of Health, entitled "Biomedical Research in the 1980's," Dr. Frederickson entitled one section "The Dwindling Bedside Connection" (3). In this section he pointed out that in 1970, M.D.s composed a little over $65 \%$ of total NIH postdoctorals. In 1980 , this figure had dropped to around $30 \%$ ! This is very distressing, and I believe very unfortunate for children, because I consider the clinical researcher an essential $\operatorname{cog}$ in the research wheel. Our clinical experiences give us a contact with reality and allow us to recognize problems that simply are not possible for the $\mathrm{Ph} . \mathrm{D}$. We must find solutions to this problem.

The final item that I want to present to you is the general dissatisfaction of pediatricians with practice. This has been a concern of mine and others for many years, but it seems to have become more acute just lately. Possibly this is due to the fact that many, if not most, pediatricians are more involved with minor illnesses and maintenance of health than was the older pediatrician, who was considered more of a specialist and dealt more with severe and life-threatening illnesses. This dissatisfaction was highlighted in a recent article by the American Academy of Pediatrics Committee on Expanding Pediatric Careers entitled "Career in Pediatrics" (1). This committee was charged with investigating this dissatisfaction that I have mentioned. They surveyed 1000 pediatricians in the United States between the ages of 40 and 75 years and found that approximately one-third of 800 respondents had already changed the direction of their work at least once. Of the 800 respondents $30 \%$ would now consider seriously an alteration in their career. The most common reason for this wish to change was a "desire for more challenge." The third most common reason given was that pediatricians felt "burned out" in their current role. The results of the study were of sufficient concern to the Academy for them to establish a plan to meet the challenge which they present. I believe that the dissatisfaction of the prac- ticing pediatrician with his or her lot should be a challenge to all of us to seek solutions to this dilemma.

I now want to turn away from this outline of problems and focus on two studies $I$ have been involved with in the last few years. Both studies were clinical in nature and were done in ambulatory pediatric settings, one in a private pediatric practice and the other in a day-care center. By describing these studies I hope to demonstrate what can be done in research in ambulatory groups away from the tertiary medical center, to suggest to you the nature of some outlets for teaching and research and hopefully to give you some ideas of how we all might approach the solutions for the other problems I have mentioned.

The first study I want to describe is an 11-year prospective study of lower respiratory tract infections in the only pediatric practice in Chapel Hill $(2,5,6)$. By investigating the clinical and etiologic features of respiratory infections in patients in this practice of a known number of children we were able to study quantitatively certain features which could not be studied in other population groups. Figure 1 shows the age-specific attack rates for lower respiratory infections, by sex, in the practice from 1964 to 1975. Figure 1 shows several things. The incidence of lower respiratory infections is related inversely to age. Lower respiratory infections are extremely common; in children under $1 \mathrm{yr}$ of age one of every four or five children was sick enough to be taken to the pediatrician. There was a preponderance of infections in boys in the preschool age. In addition, we were able to assess, in a quantitative way because we had a denominator, the relationship of certain agents to clinical syndromes and the seasonal occurrence of agents and syndromes. These observations in a pediatric practice are important for several reasons. Because we had a denominator, something that we rarely have for hospitalized patients, we were able to calculate true incidence figures. A study of patients seen by a pediatrician, is in general, a much better indicator of the impact of disease than is a study only of patients sick enough to go to the hospital. These studies also give the practitioner a reasonable way to approach and manage children with lower respiratory infections without the new and highly technical, and generally not available, laboratory methods of rapid diagnosis. Finally, they have given us ideas regarding the pathogenesis of

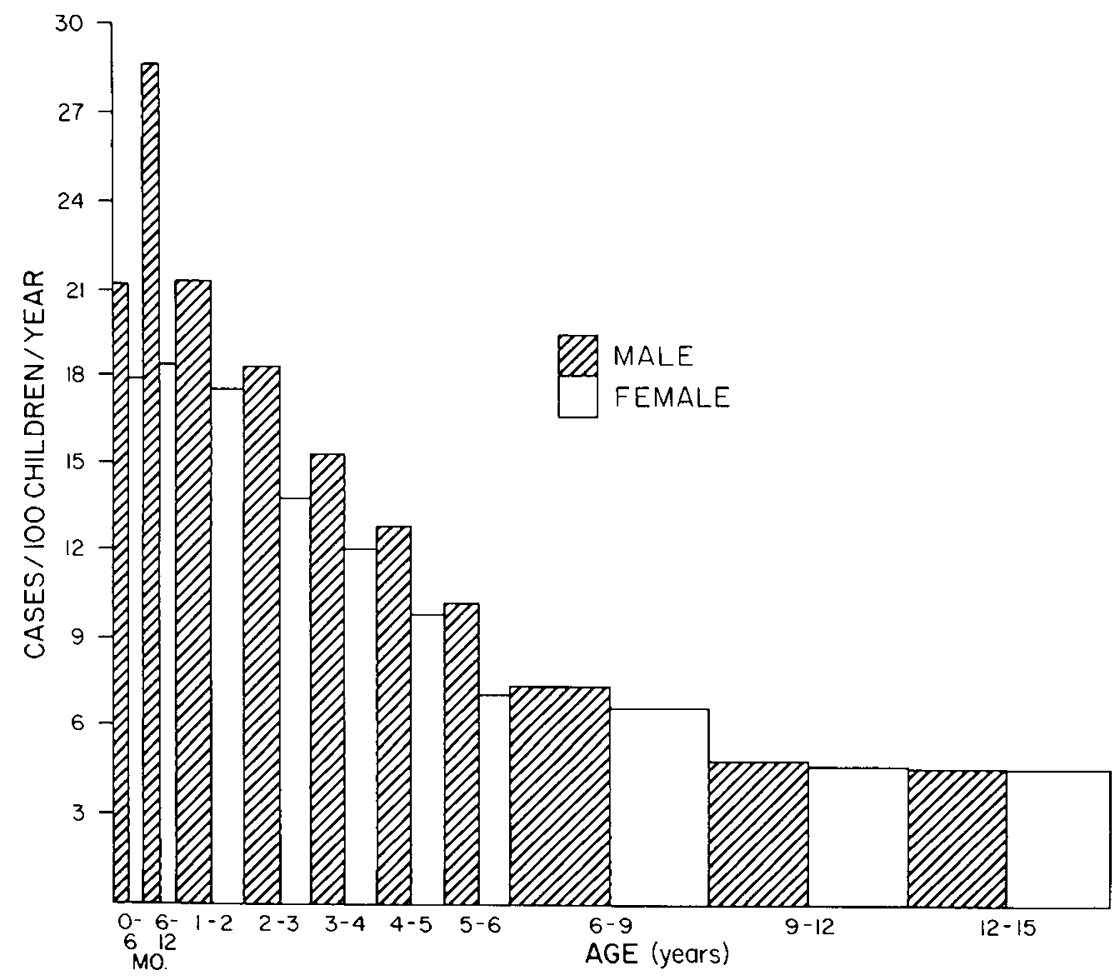

Fig. 1. Age-specific attack rates of lower respiratory tract infections in children in a private pediatric practice, Chapel Hill, NC, 1964 to 1975. 
lower respiratory infections and suggest ways we might approach the development of preventive measures.

The next study to be described is an 8-year prospective investigation of otitis media in a day-care center in Chapel Hill (4). We observed and documented all respiratory illnesses in children in this center, now with a census of 95 , and cultured ill and well children for respiratory bacteria and viruses. Since we studied the group as a whole (as a denominator), and in a prospective way, we were able to calculate rates and made certain observations that would otherwise be impossible.

Most clinicians who care for children have known for years that otitis media occurs in children who have colds. Since most colds are caused by viruses it follows that viruses should be the cause of otitis media. It has not' been possible to isolate viruses from infected ears; instead pneumococci and Hemophilus influenzae are isolated from the majority of cases; most of the rest are culturally sterile. Thus, these bacteria have been considered the cause of otitis media.

Our studies in the day-care center showed that otitis media had
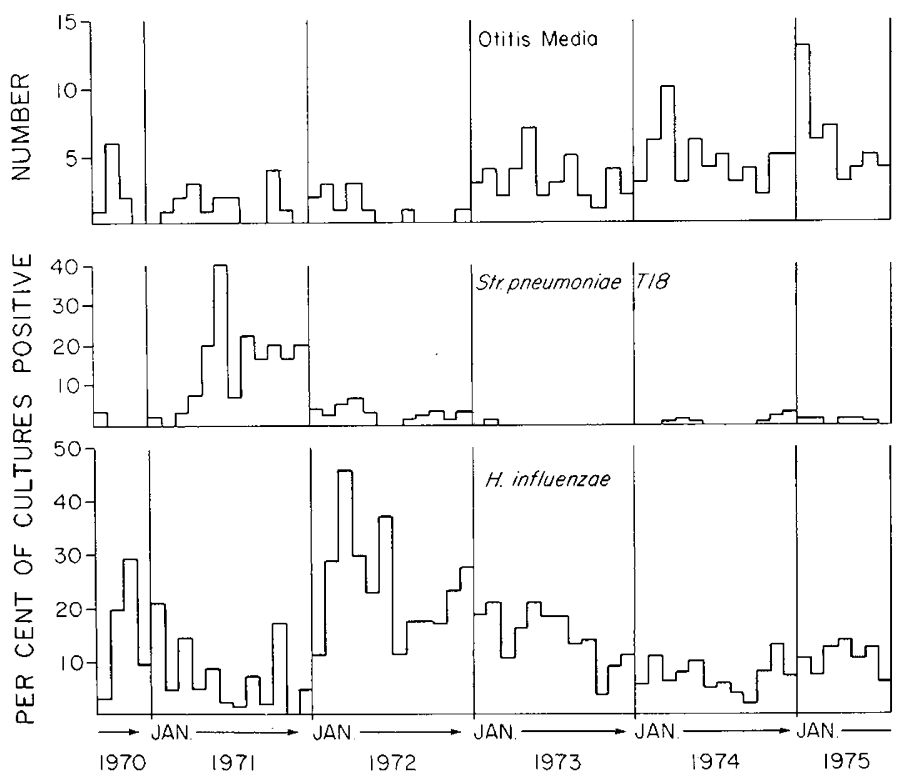

Fig. 2. Collation of acute otitis media and bacterial respiratory isolates in children in a day care center, Chapel Hill, NC, 1970 to 1975. a definite epidemiology and occurred in circumscribed outbreaks or small epidemics. Figure 2 shows this in the top frame. The middle frame shows that the isolation of type 18 pneumococcus, although it occurred in $40 \%$ of the children, was not associated with any increase in otitis media cases. Type 18 is given as an example only; other types of pneumococci followed the same pattern. The lowest frame shows the same lack of collation of the isolation of $H$. influenzae with otitis media. These observations are to be contrasted with the remarkable association between the isolation of viruses and the occurrence of otitis media, as shown in Figure 3. The top frame shows again that otitis media occurs in outbreaks. The middle frame shows the isolation of respiratory syncytial virus and the bottom frame the isolation of influenza. and parainfluenza viruses. It is obvious that there was close collation between these viruses and otitis media. The adenoviruses demonstrated this association as well but are not shown here.

These studies documented what we always thought, that viruses are the primary cause of otitis media and suggested that bacteria are secondary invaders only. Whether or not pneumococci or $H$. influenzae are involved in otitis media apparently depends entirely on their being present in the respiratory tract when a viral respiratory infection occurs. These observations have changed our thinking about otitis media, its pathogenesis and its prevention. We believe that if we are going to prevent otitis media we must prevent viral infections; if this can be done the bacteria present in the upper respiratory tract probably will present few problems.

These studies were done in population groups away from any hospital, one in pediatric private practice, the other in a day-care center. I hope these suggest to you, as they do to me, that such groups might be more useful than currently thought for research purposes and also for teaching. I should like to pursue this possibility further and suggest that the use of such populations might be essential to pediatrics in the future. If $I$ am correct in this postulation then we must consider how we are to proceed in accomplishing this marriage between academic departments, the practice of pediatrics and various institutions housing or caring for children. Time does not permit my discussing details of how I think this can be done, but I want to emphasize that I believe all pediatricians, irrespective of the nature of their work, must join hands in this venture. We must develop new populations for teaching and research, we must do more clinical research to solve the problems of clinical practice and in the utilization of new technologies, and we must train more people in how to do this research. In so doing I am of the opinion that all of us, but particularly the practicing pediatrician, will have a feeling of

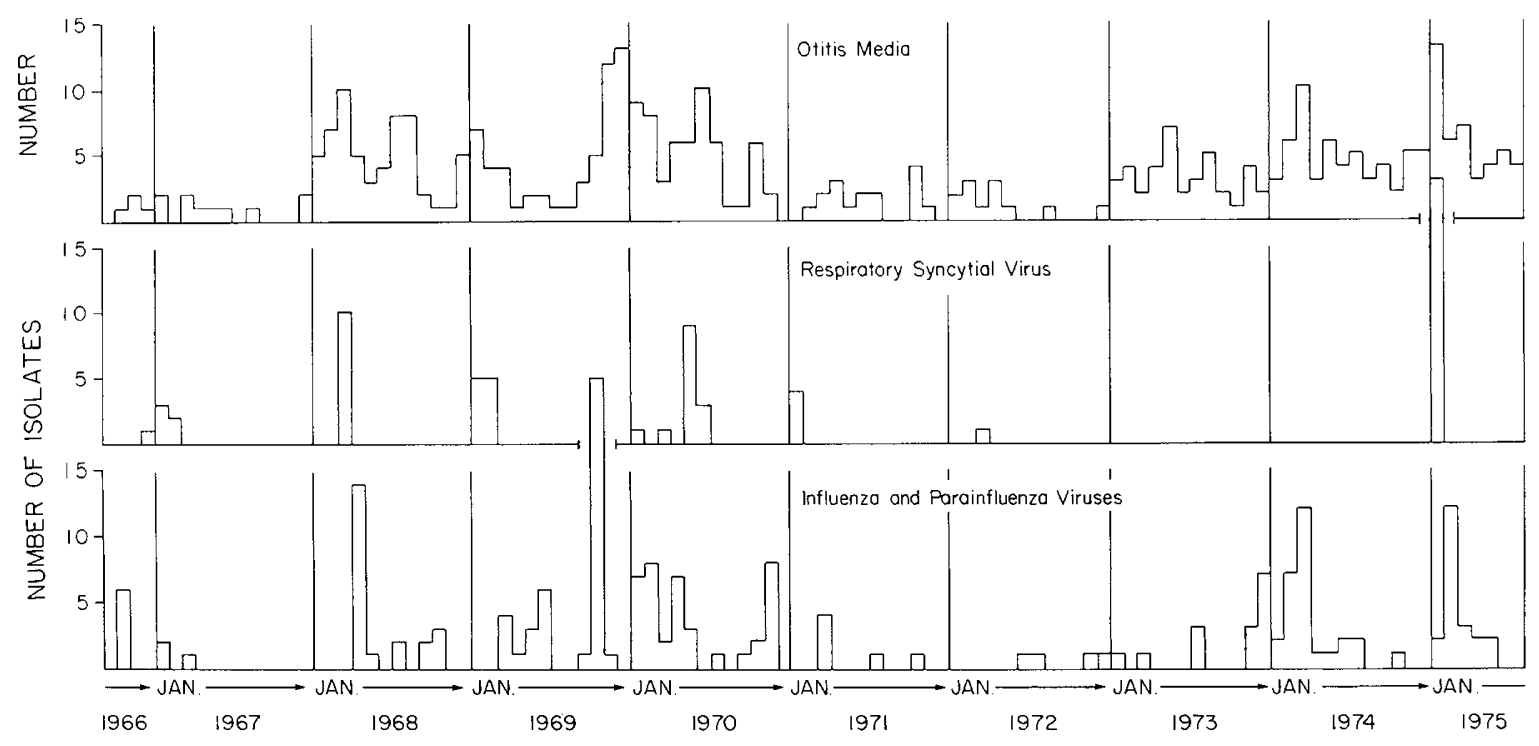

Fig. 3. Collation of acute otitis media and viral respiratory isolates in children in a day care center, Chapel Hill, NC, 1966 to 1975. 
greater satisfaction and thus be happier with his or her lot. I would like to expand on these ideas with reference to the concerns I raised earlier.

How will this help in our lack of knowledge of how to use biomedical information? I go on record that I believe that this is the most important problem faced by clinical medicine today. If we pediatricians accept that premise and work together we can start making a master plan for approaching this problem in the future. Only by such forward planning can we possibly be successful.

I suggest to you that pediatric practices, schools, day-care centers, health departments, and institutes for the care of the handicapped are sites for pediatric teaching and research. Many types of teaching and research can be done only in such populations. Formidable problems face us if we are to be successful in this effort. It is logistically hard to work in such groups-much more difficult than with hospital patients. When this is coupled with the increasing difficulty in doing clinical research in this country it is easy to become discouraged. We cannot let this happen. Those of us in academia, in practice, or working with children in municipal, county, state, or federal institutions must join in a concerted effort to provide new outlets for teaching and research.

I hope that the efforts mentioned might help in increasing the number of pediatricians choosing academic careers and reverse the declining interest in clinical research. I am rather pessimistic that we will entice young people to enter academia until we can remove money as a factor in choosing a career. This remains a problem for which I have no ready answer. With reference to clinical research, I suggest that we join hands with the Ph.D. and the basic scientist and do our studies collaboratively. We have found this to be very successful, a lot of fun, and all of us seem to profit.

I am sure it is clear to you that I believe the pediatric practitioner will be more satisfied if he or she can be a more integral part of all of pediatrics, can be challenged by teaching students and house staff and enjoy the many thrills that come with adding new knowledge to pediatrics. I should like to elaborate a bit on these. If the pediatric practitioner is to become part of the academic scene several things must happen. First, those of us in academia must accept those in practice as essential parts of our teaching and research programs. Similarly, those in practice must accept this relatively new role for themselves. The practitioner must realize that teaching skills have to be developed and that teaching takes time and slows down the pace of most private offices. If the practitioner is going to be involved in research, training programs directed toward this goal will have to be designed. I am not unaware of the problems in doing research in a practice setting. Probably the best way for this to come about is by collaboration between those in academia and those in practice. For the person in practice to be a vital part of any such effort, however, it will be essential that he or she has had previous research training.

All of this is not going to come easily. I have suggested the logistical, societal, and even legal problems in attaining these. There will be problems in preparing our young physicians to assume the roles I have outlined. In addition to the usually accepted training in clinical pediatrics, in pediatric subspecialties, or in research, I believe we must pay more attention to training in epidemiology and biostatistics. Unfortunately, these have been neglected rather badly in many medical curricula. This has led to widespread inability of students, house staff, clinicians, and clinical researchers to interpret medical literature properly, to understand sufficiently the variability of patients and their diseases, and to do good clinical research. Biostatistics are so important in modern medicine that they need no defending. It is tough for many of us but we must be familiar with what biostatistics offer the modern physician and researcher. Epidemiology, however, presents a whole new set of problems. For some reason epidemiology has never been popular with medical students and I am shocked on occasion with the inability of some medical students, house staff, or even faculty to grasp even the most elementary epidemiologic principles. Even so, I believe this is one of the very potent tools that we must use to help us solve some of the problems that have been discussed. This might not be easy. The plight of epidemiology was emphasized in a recent editorial in the $\mathrm{New}$ England Journal of Medicine by Dr. Kenneth J. Rothman entitled "The Rise and Fall of Epidemiology, 1950-2000 A.D." (7). Written from the time perspective of 2000 AD, Dr. Rothman described the slow birth of epidemiology during the 300 years before the 20th century, its blossoming between 1950 to 1980 , and its decline thereafter. This decline was due to many things, including the rising of public sentiment for privacy, the bureaucractic implementation of arbitrary rules forced upon institutional review boards, the time and cost of doing epidemiologic research, and the political implications which derived from some types of epidemiologic research, such as the harmful effects of inhaled pollutants and food additives. Rothman predicted that by 1990 epidemiology would be largely forgotten by science. I hope he is wrong but his editorial does indicate that epidemiology is in trouble. If I am right and epidemiology is critical to future research in pediatrics, then we must not, we cannot let this happen.

In summary, I hope I have convinced you that research, as well as teaching, is important to all pediatricians and that all of us have a responsibility to work together to learn how to use modern technology, to provide new outlets for research and teaching, and to reverse the declining trends to choose academic careers and do clinical research. By so doing, all of us, particularly the practicing pediatrician, should be more satisfied that we are part of the most worthwhile specialty in medicine. The aim of all of us, the improvement in the health and welfare of children, will surely follow.

Again, I thank you for the privilege of being your President and for allowing me to share with you some of my thoughts and concerns.

\section{REFERENCES AND NOTES}

1. American Academy of Pediatrics Committee on Expanding Pediatric Careers: career in pediatrics. Pediatrics, 64: 259 (1979).

2. Chapman, R. S., Henderson, F. W., Clyde, W. A., Jr., Collier, A. M., and Denny, F. W.: The epidemiology of tracheobronchitis in pediatric practice. Am. J. Epidemiol., (in press).

3. Frederickson, D. S.: Biomedical research in the 1980s. N. Engl. J. Med., 304: 509 (1981)

4. Henderson, F. W.: (unpublished data).

5. Henderson, F. W., Clyde, W. A., Jr., Collier, A. M., and Denny, F. W.: The etiologic and epidemiologic spectrum of bronchiotitis in pediatric practice. J. Pediatr., 95: 183 (1979).

6. Murphy, T. F., Henderson, F. W., Clyde, W. A., Jr., Collier, A. M., and Denny, F. W.: Pneumonia: an eleven year study in pediatric practice. Am. J. Epidemiol., 113: 12 (1980)

7. Rothman, K. J.: The rise and fall of epidemiology 1950-2000 A.D. N. Engl. J. Med., 304: 601 (1981).

8. The Task Force on Pediatric Education: The Future of Pediatric Education. pp 19-29.

9. Presidential Address presented before the American Pediatric Society, San Francisco, California, April 28, 1981.

10. The author is indebted to my colleagues, R. M. Christian, W. A. Clyde, Jr., A M. Collier, W. G. Conley, III, A. S. Dajani, G. W. Fernald, W. P. Glezen, F. W. Henderson, R. P. Lipman, F. A. Loda, T. F. Murphy, R. S. Senior, C. I Sheaffer, and R. I. Slotkin for assistance with the reported studies.

11. This research was supported by SCOR Grant HL19171 from the National Heart, Lung and Blood Institute, Training Grant AI07151 from the National Institute of Allergy and Infectious Diseases, Cooperative Agreements R806514 and R806706 from the Environmental Protection Agency, and Contracts 68-023403 and 68-02-3404 from the Environmental Protection Agency. 